\title{
SAFETY ASSESSMENT OF ADJACENT ROADS SECTIONS VIA MAXIMUM ENTROPY DRIVERS PERCEPTION FIELD
}

Characteristics have been developed, by which the boundaries of coherence of adjacent road sections are established in accordance with requirements for the traffic safety. The coordination of adjacent sections of the road is carried out taking into account the driver's behavior program, which is presented in the work as a value of the maximum entropy of his perception field. The choice of this criterion is determined by the possibility of a comprehensive assessment of many road environment factors that influence the driver. The boundaries of coordination of the maximum entropy values of adjacent road sections with use of the accident rate are established.

Keywords: adjacent road sections, maximum entropy, matching characteristics, accident rate

\section{Introduction}

At the present stage of development of transport engineering, the system arrangement of the road environment is the main means of ensuring the traffic safety. Approaches to reducing accidents, due to technical means of organizing the traffic, have practically exhausted themselves [1]. At the same time, existing approaches can be improved and supplemented, taking into consideration the human factor in assessing their safety [2]. The movement of the driver is carried out in the road environment, which includes various elements of engineering and technical support [3]. A drastic change in traffic conditions, when moving from one section of the road to another, can negatively affect the functioning of the driver [4-6]. Constant adaptation of the driver to changing conditions contributes to development of fatigue, causes his erroneous actions and as a result, leads to the creation of emergency situations. Therefore, it is necessary to organize such traffic conditions that, on the one hand, would not create undesirable transient phenomena in the driver's body and provide all the necessary information to select the right actions as a result of driving. This requires a comprehensive assessment of factors of the road environment acting on the driver and the development of a method for coordinating traffic conditions on adjacent sections of roads (Human-Surrounding interface).

The article consists of the following sections: the first section provides an analysis of the literature and identifies major shortcomings of existing approaches to infrastructure design; in the second section is presented an analysis of scientific researches is revealed, which revealed shortcomings of certain methods of the traffic safety assessment; in the third section, for designing the infrastructure of the road environment, taking into account the human factor, a method is proposed consisting in assessing traffic safety by the consistency of adjacent sections of roads. Maximum entropy is chosen as the criterion. An accident rate was used to assess the danger of the road infrastructure, which was determined on the basis of statistics on road accidents over 5 years and the volume and composition of traffic flow; in the fourth section experimental studies were conducted to determine the values of the maximum entropy, on three roads with a length of 45 kilometers with participation of 26 drivers. During the movement of cars, traffic factors and speed were recorded. During the processing of the survey results, the length of the driver's perception field was calculated according to the empirical formula, depending on the speed of movement. Within each field of perception, the number of factors of the road environment was determined by which the value of the maximum entropy was calculated.

According to dependence of the maximum entropy on the accident rate, an information content of the maximum entropy has been proved in terms of traffic safety. To coordinate adjacent sections of roads, the ratio of values of the maximum entropy of the previous and subsequent sections is applied. Dependence of these relations on the accident rate and application of the hazard limits of the accident rate, established by the regulatory document of Ukraine, allowed to establish the limits of the maximum entropy changes that characterize sections of the road as safe, low-risk, dangerous or very dangerous.

\section{Analysis and statement of the research problem}

When examining the road environment, scientists usually consider the safe combination of the individual

\footnotetext{
Nadiia Kulbashna ${ }^{1}$, Iryna Lynnyk ${ }^{2}$, Andrii Galkin ${ }^{3, *}$, Oleksii Prasolenko ${ }^{3}$, Sergii Dulfan ${ }^{3,4}$

${ }^{1}$ Departament of Electric Transport, O. M. Beketov National University of Urban Economy in Kharkiv, Ukraine

${ }^{2}$ Department of Urban Construction, O. M. Beketov National University of Urban Economy in Kharkiv, Ukraine

${ }^{3}$ Department of Transport System and Logistics, O. M. Beketov National University of Urban Economy in Kharkiv, Ukraine

${ }^{4}$ Department for Infrastructure of Kharkiv City Council, Ukraine

*E-mail of corresponding author: galkin.tsl@gmail.com
} 
elements of the plan and profile of the road. Thus, in [7] the distribution of the roads, according to homogeneous geometric characteristics and the mandatory reduction of the deviations of the speeds in the adjacent sections, is proposed. In [8] is proposed to use the length of the driver's perception field as sections of the road, taking into account variables and constant factors of the road environment. Influence of road gradients on other traffic parameters is studied in [4]. It is indicated that the value of the vehicle's initial speed of entry to an adjacent section of the road is a significant parameter, changes of which may be a criterion for the consistency of structures on road sections. The methods proposed in the works [4, 7-8], despite their simplicity and practicality, are limited by the number of criteria and do not contain a systematic assessment.

In [1] the condition of the roadway is taken as a characteristics that affects the accident rate. A systematic approach was used, consisting in study of relationship of the four elements: driver's behavior, vehicle conditions, roadway bed and environment. In particular, in [9] is indicated that a modern approach to ensure the road safety and reduce the risks of traffic participants getting into the road transport aaccident, is a reconstruction of the road environment. However, the issue of the traffic safety, which was considered, does not concern individual sections, but the road as a whole.

The cluster analysis was used to investigate the traffic conditions in road sections in [10]. The sections of roads with similar characteristics were determined and the speed was used as a criterion. Despite the need to harmonize adjacent sections of roads, the method has not been developed.

The closest to solving the problem of ensuring the traffic safety on adjacent sections of roads is the work by Babkov [11]. It uses the method of plotting speeds and defines the requirements for divergence of the safe speeds on adjacent sections of roads. The criterion is the value of the safety factor, which is the ratio of the speeds of traffic in adjacent areas.

A similar approach was considered in [2], where a speed that correlates well with the driver's heart rate variability is selected as an indicator of the driving safety. An assessment of the conditions is proposed: good consistency, which does not require reconstruction of the road sections; average consistency requiring minor adjustments to conditions; poor consistency with poor road safety, requiring the road section reconstruction.

In [5] is proved that unsatisfactory traffic conditions on the road sections cause an increase in the emotional tension of the driver, which affects the reduction of the speed of movement.

Based on the principle of interaction between the driver and the road environment, intelligent systems are developed to help the driver to ensure the safety of the vehicle. Thus, the problems associated with implementation of autonomous vehicles are discussed in [12]. Accounting for interaction of the driver with the road environment in the case of vehicle automation was also considered in [13].
A number of key problems are described that arise due to the fact that automated systems are not always reliable and the process of error management in the context of human interaction and automation is not well understood. Author of [3] proposes implementation and analysis of algorithms to identify static and dynamic objects of the road environment using the visual perception module, which relates to the driver's assistance system.

Therefore, despite the benefits of the latest means of driving safety, the task of organizing a human-centered road environment cannot be overlooked. Orientation to ergonomic design and reconstruction of the road environment allows to take into account the psychophysiology of the driver and create a comfortable movement on the road, which, like the vehicle, is the place of his work.

Research presented in [6] showed that result of the directional control of the driving conditions is the speed adjustment, which provides drivers with an opportunity to choose easier and more convenient driving modes during driving. The algorithm of regulation of functional norms of speed of movement by means of the directed influence on the conditions of movement within each field of perception of the driver is developed. However, this work does not consider a modal assessment of changes in these indicators along the road.

Despite the fact that the speed is a result of the purposeful activity of the driver in the road environment, it cannot be considered as a complex criterion. The need for a systematic assessment arises because it is necessary to take into account many factors of the road environment acting on the driver.

The choice of a complex criterion at the present stage of the study of interaction of the system «driver - vehicle - road environment» components should be based on systems theory and theory of information [14]. With the aim of purposeful optimal control of the complex dynamic systems, which include, in particular, the road environment, methods of the system theory evaluate the fundamental relationships between individual elements and the whole system, as a whole [15]. This provides an opportunity to evaluate results of the complex impact of the traffic environment on the driver of a vehicle.

Thus, in the work [16], on predictability of driver's behavior in certain road conditions, forecast models for reducing congestion in urban roads were developed. The speed of movement on individual sections of roads is also used as a criterion and information entropy, which characterizes the time series of speeds on each section of the road, was used to quantify the speed uncertainty. To determine the state of traffic, it is proposed to use the random entropy, which takes into account the number of speed states [15], temporary entropy to estimate the probability of not exceeding the speed and the actual entropy that establishes the sequence of states of the road section [17]. In [18] are evaluated regularities of the influence of the information flow on the driver's work in the “«driver - vehicle - road environment»» system. However, 


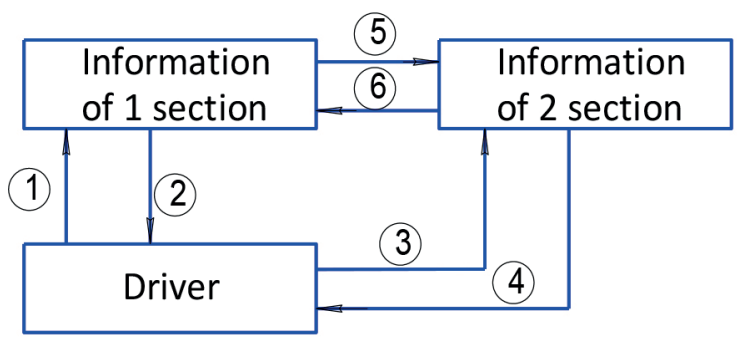

Figure 1 Scheme of coordination of the traffic conditions on adjacent sections of roads

studies do not address the issue of consistency of the entropy parameters in adjacent sections of roads.

The most productive for harmonizing the parameters of adjacent sections of the road is the concept presented in [19]. The concept is based on coordination of the drivers behavior programs, which are carried out by selecting values of the next section's setting. Coordination of programs' means that it is necessary to select such elements of the traffic environment in another section, which, at the moment of transition from section to section, will not lead to undesirable transients. According to the proposed concept, in [20] the behavior programs on adjacent sections of the road were presented in the form of harmonization of entropy parameters. This approach makes it possible to take into account the states and components of the «driver - vehicle - road environment». But the proposed concept does not have a developed method, so it needs further study.

Thus, research has shown that the available methods of assessing the road safety do not sufficiently take into account influence of all the factors of the road environment on the driver. A systematic approach to determining the driver's interaction with the road environment has not been developed and, therefore, they may not be basic to ensure the road safety.

Therefore, there is a need, on one hand, to evaluate the influence of road factors of road sections on the driver by complex indicators. On the other hand, according to the indicators obtained, it is necessary to resolve the issues of coordination of sections of the road environment when moving a vehicle from one section of the road to another.

The purpose of this article is to develop an assessment of the safety of adjacent road sections by the maximum entropy of the driver's perception field.

To achieve this goal it is necessary to solve the following problems:

- draw up a coordination plan for adjacent sections of roads on the information links of the driver's interaction with the road environment;

- to offer the criterion of complex information influence of the road environment on the driver;

- based on the experimental studies to determine dependence of the accident rate on the maximum entropy of the field of perception of the driver;
- to develop an assessment of the coordination of traffic conditions on adjacent road sections by the maximum entropy of the driver's perception field.

\section{$3 \quad$ Materials and methods}

\subsection{The coordination scheme of adjacent sections of the road}

The harmonization process of adjacent sections of roads is performed according to connections, which are schematically shown in Figure 1. Considering the subsystem «driver - road environment» in the general system «driver - vehicle - road environment», it is necessary to ensure coordination, which is in accordance with the information characteristics of the driver's perception field to his requirements of comfort and safety. For this purpose, connections 1 and 2 must be realized (Figure 1). That is, through these connections, the driver's activities are consistent with the road environment of a certain section of the road. Moving to the next section, the driver interacts with another road environment (connections 3 and 4, Figure 1), which has a new information load. These new informational impacts should also be consistent with the driver's activities. To coordinate conditions of the road environment in adjacent areas, connections 5 and 6 are used (Figure 1). Based on these connections, information parameters of adjacent sections are brought into correspondence; they were previously aligned with the requirements of the driver.

Therefore, in order to coordinate adjacent sections of roads, it is first necessary to select the parameter according to which the activity of the driver is consistent with the road environment and then proceed to the coordination of this parameter in the adjacent sections.

It is proposed to use the maximum entropy of the driver's perception field as a criterion for providing the necessary conditions for the traffic on the road sections [19]. The driver's behavior program on adjacent sections of the road is considered while driving in a column when the driver's coordinates are unchanged and can be expressed as:

$V^{(1)}-V_{\Sigma H}^{(1)}=0 ; \quad V^{(2)}-V_{\Sigma H}^{(2)}=0$, 
and in free mode (overtaking) when the driver's coordinates change. Then the behavior programs can be expressed as follows:

$$
X^{(1)}-X_{\Sigma H}^{(1)}=0 ; \quad X^{(2)}-X_{\Sigma H}^{(2)}=0,
$$

where:

$X^{(1)}, X^{(2)}$ - the actual distances from the vehicle to the edge of the roadway in the cross section of the road in the first and second sections, respectively;

$V^{(1)}, V^{(2)}$ - the actual vehicle speeds in the first and second sections, respectively;

$X_{\Sigma H}^{(1)}, X_{\Sigma H}^{(2)}$ - individual norms of the provisions of vehicles in the cross section of the road of the first and second sections, respectively;

$V_{\Sigma H}^{(1)}, V_{\Sigma H}^{(2)}$ - individual norms of speeds of movement of the first and second sections, respectively.

It was proved in the work [20] that individual rate norms can be expressed in terms of the maximum entropy $H_{m}$, then for matching the adjacent sections it is necessary to satisfy the condition of equality of the maximum entropies of the first and second sections. In 20] was also indicated that for coordination of the adjacent sections it is not necessary to provide the same road parameters. It is enough that their total informational impact on the driver in the second section is equal to the informational impact in the first section.

Therefore, harmonization of adjacent road sections implies that the maximum entropy of the next section $H_{m(n+1)}$ and the previous $H_{m(n)}$ is minimized.

\subsection{Estimation of the consistency of adjacent sections of the road}

The length of the field of perception was determined by the empirical formula in different sections [21]:

$$
L=15+4.3 \cdot V
$$

where: $L$ - length of the driver's perception field, m; $V$ - car speed (actual entry speed), $\mathrm{km} / \mathrm{h}$.

During the processing of the experimental data, the maximum entropy of the driver's perception field was estimated by formula [22]:

$H_{m \Pi C}=n^{2}$.

where:

$H_{m \Pi c}$ - maximum entropy of the field of perception;

$n$ - the number of objects in the field of perception.

When processing the experimental data, it was also necessary to estimate the maximum entropy in terms of the traffic safety. For this purpose, the influence of accident rate on maximum entropy was estimated.

It is a common method of estimating the risk of a section of a road by the number of traffic accidents (road accidents), so during the data processing of the experiment the data on road accidents that happened over five years were used.

Based on the number of accidents, the aaccident rate was calculated according to the following formula [23]:

$K_{n p}=\frac{10^{6} \cdot Z}{365 \cdot L_{y} \cdot I}$

where:

$K_{n p}$ - accident rate coefficient, accidents/1 million auto/ $\mathrm{km}$ mileage;

$Z$ - number of accidents during the year;

$I$ - average annual daily traffic volume in both directions, auto/day;

$L_{y}$ - length of the road section, $\mathrm{km}$.

The volume and composition of the movement were estimated using the moving observer method [23]. According to this method:

$I=\frac{n_{\varepsilon}+\left(n_{\delta}-n_{M}\right)}{t_{n}+t_{o}}$,

where:

$I$ - traffic volume, auto/h; $n_{\varepsilon}$ - number of oncoming cars;

$n_{\delta}$ - the number of cars overtaking the experimental vehicle;

$n_{M}$ - the number of cars overtaken by the experimental vehicle;

$t_{n}$ - travel time in the forward direction, hrs;

$t_{0}$ - travel time in the opposite direction, hrs

The obtained values of the accident rate with use of Equations (5), (6) were used during the processing of the experimental data.

\section{Results}

\subsection{Results of experimental research}

The experimental races were carried out in the field conditions on three roads with length of $20,15,10$ kilometers, respectively:

- $\quad$ Road 1. The width of the roadway ranges from 7.0 to $10.5 \mathrm{~m}$, the road has two or three lanes, axial marking is applied. The coefficient of adhesion of the car wheel with road surface is $0.39-0.41$, the volume factor is 1.03-1.27;

- Roads 2 and 3. The width of the roadway is $7.0 \mathrm{~m}$, the width of the roadbed is $12.0 \mathrm{~m}$, the height of the embankments and the depth of the notches do not exceed $1.0 \mathrm{~m}$; there are two lanes, there is an axial marking.

Experimental studies in the field conditions were conducted in the summer in the same weather conditions (dry, sunny, air temperature in the cab $-22-26{ }^{\circ} \mathrm{C}$ ).

The studies used passenger cars. Test drivers with 3-7 years of experience and aged from 25 to 45 years were involved in the field experiments. In the course of the experimental races, the actual speed of movement, the 


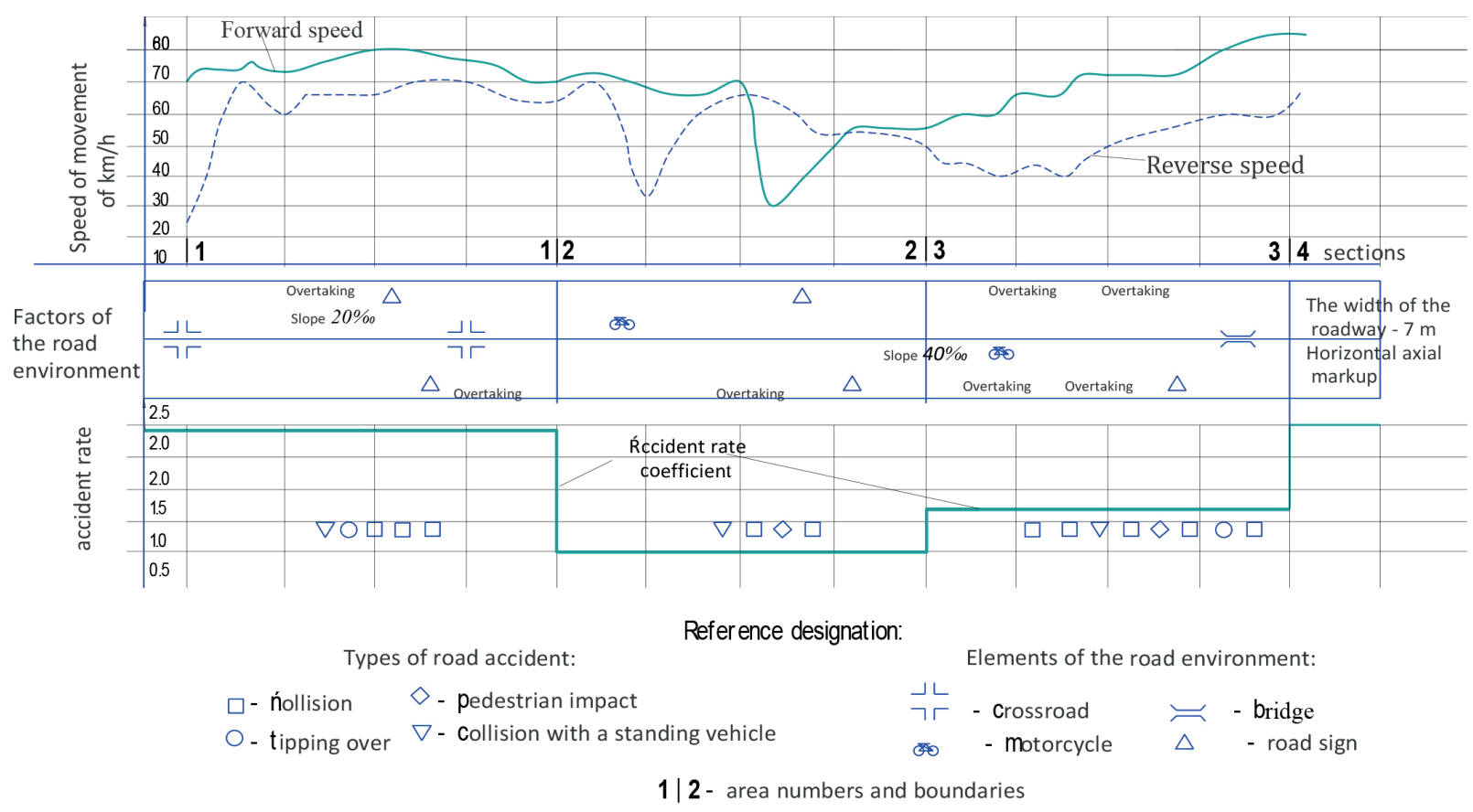

Figure 2 Fragment of a linear graph of the road 1

Table 1 Assessment of experimental data on the road 1

\begin{tabular}{|c|c|c|c|c|c|c|c|c|}
\hline Section & $\begin{array}{l}\text { The length of the } \\
\text { field of perception, } \\
\text { m }\end{array}$ & $V, \mathrm{~km} / \mathrm{hrs}$ & $n$ & $H_{m \Pi \mathrm{C}}$ & $H_{m}$ & $\begin{array}{l}\text { Volume of daily } \\
\text { traffic, aut/h; }\end{array}$ & $\begin{array}{l}\text { Number of road } \\
\text { accidents for } 5 \\
\text { years }\end{array}$ & $K_{\Pi t}$ \\
\hline \multirow{3}{*}{1} & 325 & 72 & 6 & 36 & \multirow{3}{*}{44.67} & \multirow{3}{*}{2107} & \multirow{3}{*}{5} & \multirow{3}{*}{1.3} \\
\hline & 344 & 76.5 & 7 & 49 & & & & \\
\hline & 331 & 73.5 & 7 & 49 & & & & \\
\hline \multirow{4}{*}{2} & 316 & 70 & 10 & 100 & \multirow{4}{*}{52.5} & \multirow{4}{*}{1154} & \multirow{4}{*}{4} & \multirow{4}{*}{1.8} \\
\hline & 221 & 48 & 5 & 25 & & & & \\
\hline & 230 & 50 & 7 & 49 & & & & \\
\hline & 258 & 56.5 & 6 & 36 & & & & \\
\hline \multirow{3}{*}{3} & 303 & 67 & 7 & 49 & \multirow{3}{*}{73} & \multirow{3}{*}{548} & \multirow{3}{*}{8} & \multirow{3}{*}{2} \\
\hline & 325 & 72 & 11 & 121 & & & & \\
\hline & 350 & 78 & 7 & 49 & & & & \\
\hline \multirow{3}{*}{4} & 368 & 82 & 6 & 36 & \multirow{3}{*}{41.67} & \multirow{3}{*}{884} & \multirow{3}{*}{3} & \multirow{3}{*}{1.86} \\
\hline & 288 & 63.5 & 5 & 25 & & & & \\
\hline & 273 & 60 & 8 & 64 & & & & \\
\hline \multirow[t]{2}{*}{$\cdots$} & $\cdots$ & $\cdots$ & $\ldots$ & $\cdots$ & \multirow[t]{2}{*}{$\ldots$} & \multirow[t]{2}{*}{$\ldots$} & \multirow[t]{2}{*}{$\cdots$} & \multirow[t]{2}{*}{$\ldots$} \\
\hline & 252 & 55 & 7 & 49 & & & & \\
\hline \multirow[t]{2}{*}{20} & 252 & 55 & 9 & 81 & \multirow[t]{2}{*}{48.7} & \multirow[t]{2}{*}{945} & \multirow[t]{2}{*}{3} & \multirow[t]{2}{*}{1.74} \\
\hline & 253 & 55 & 4 & 16 & & & & \\
\hline
\end{tabular}

travel time of the sections and their length, as well as the factors of the road environment, were recorded.

The data of the experiment were analyzed and processed in acomplex on the linear graphs of the investigated roads. A fragment of the linear graph of the road 1 is shown in Figure 2.

While processing the experimental results, the road was divided into sections that were equal to the length of the driver's perception field.
Due to the fact that for an assessment of each driver's perception field $H_{m}$ there are insufficient statistical data on road accidents, $3-4$ perception fields were combined so as to obtain sections of the same length (approximately one kilometer), and the maximum entropy of the driver's perception field was taken as the average of the totality of these values on the site $H_{m п c}$. Assessment of the road sections 1 is presented in Table 1. 


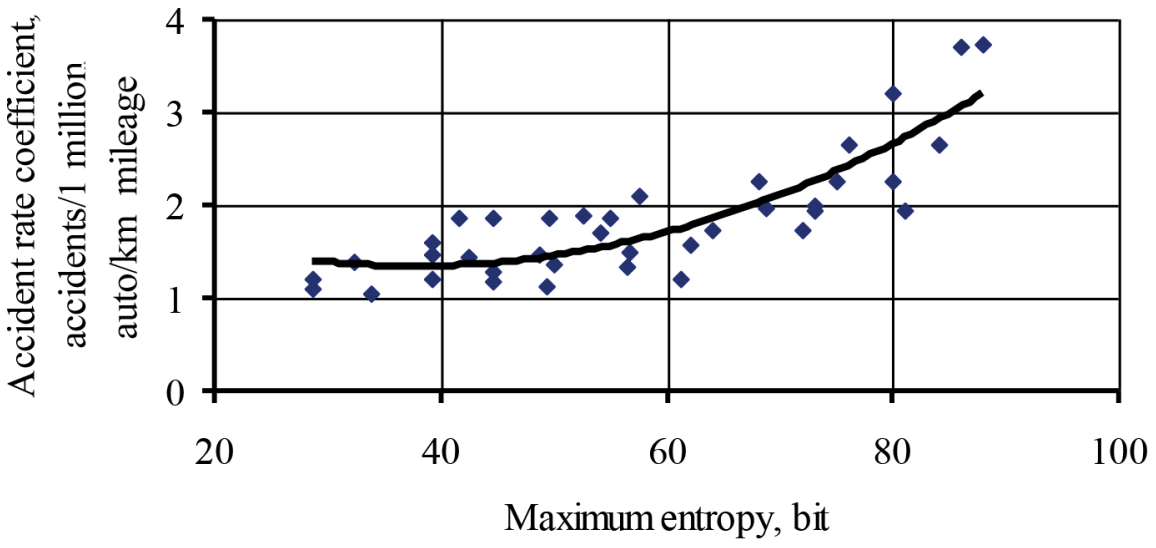

Figure 3 Dependence of the accident rate on the maximum entropy of the driver's field of perception.

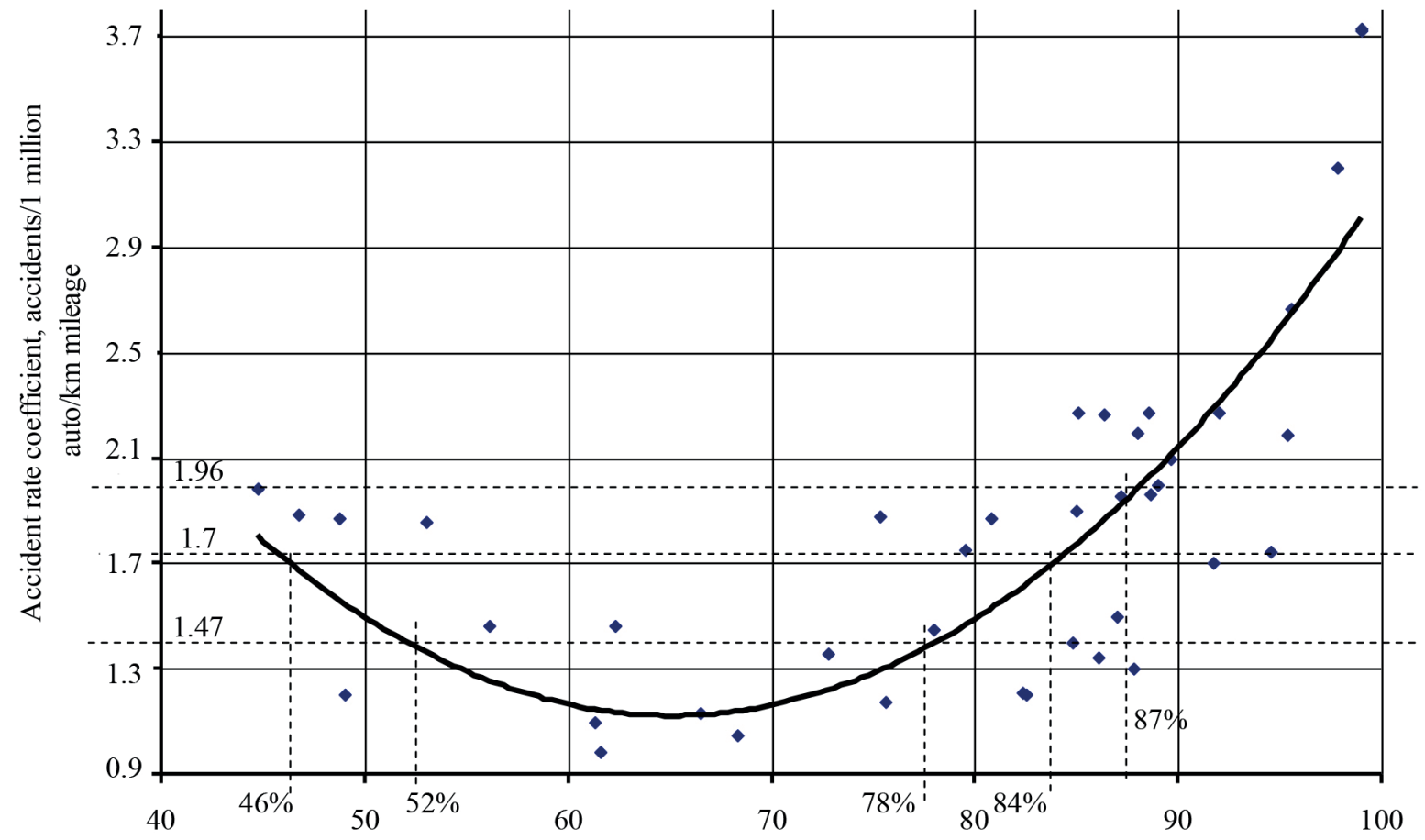

The ratio of the maximum entropy values of adjacent areas

Figure 4 Dependence of the accident rate coefficient on the ratio of values of the maximum entropy of adjacent areas

\subsection{Processing the data}

According to results of Table 1 , as well as results of evaluation of roads 2 and 3 (which are not presented), dependence of the accident rate $K_{n p}$ on the maximum entropy of the field of perception of the driver $H_{m}$ (Figure 3 ) is estimated, which estimates the degree of danger of the conditions of road sections.

Analysis of the empirical data proved the curvature of the nature of the relation $K_{n p}=f\left(H_{m}\right)$ (Figure 3). The following regression equation was obtained by processing the experimental data using the method of least squares:

$K_{n p}=0.0007 H_{m}^{2}-0.056 H_{m}+2.4$.
A correlation index of $r^{\prime}=0.851$ indicates a high bond density, the probability of which was estimated by the Student's t-test. The quadratic error $m_{\eta}=0.085$, the reliability criterion $t_{T}=10.01$ is greater than the tabular $t_{p}=2.7$ for $0.01 \%$ coverage, which indicates the reliability of the correlation index. Thus, the maximum entropy of the driver's perception field is an indicator of the traffic safety on adjacent road sections.

The relation $\left(H_{m(n)} / H_{m(n+1)}\right)$, where $H_{m(n)}$ and $H_{m(n+1)}$ are values of the maximum entropy of the field of perception of the previous and next sections, respectively, was used to harmonize adjacent road sections in the free mode. This ratio is in line with the accident rate. Analysis of the empirical data proved the curvature of the bond $K_{n p}=f\left(H_{m(n)} / H_{m(n+1)}\right)$, which is presented in Figure 4. 
Table 2 Estimation of indicators of the traffic conditions consistency on adjacent sections of roads by the driver's perception field maximum entropy

\begin{tabular}{cccc}
\hline Section safety assessment & $\begin{array}{c}\text { Value of the accident rate, according to } \\
{[24]}\end{array}$ & $\begin{array}{c}\text { Ratio of the maximum entropy } \\
\text { values }\end{array}$ & $\begin{array}{c}\text { Assessment of sections } \\
\text { consistency }\end{array}$ \\
\hline Dangerous & $1.71 \ldots 1.96$ & Less than $46 \%$ & Aligned \\
Low-risk & $1.45 \ldots 1.71$ & $46 \ldots 5 \%$ & Aligned \\
Safe & Less than 1.45 & $52 \ldots 7 \%$ & $78 \ldots 84 \%$ \\
Low-risk & $1.45 \ldots 1.71$ & $84 \ldots 87 \%$ & Aligned \\
Dangerous & $1.71 \ldots 1.96$ & More than $87.0 \%$ & Not aligned aligned \\
Very dangerous & More than 1.96 & & N
\end{tabular}

Processing the experimental data using the least squares method allowed us to obtain the following regression equation:

$$
K_{n p}=0.0016\left(H_{m(n)} / H_{m(n+1)}\right)^{2}-
$$$$
-0.214\left(H_{m(n)} / H_{m(n+1)}\right)+8.081 \text {. }
$$

The density of the relationship between the accident rate and the ratio $H_{m(n)} / H_{m(n+1)}$, was estimated by the correlation index $r^{r}=0.785$. Since the value of $r^{\prime}$ is large, the hypothesis that there is a close bond $K_{n p}=f\left(H_{m(n)}\right.$ $\left.H_{m(n+1)}\right)$ is confirmed. The reliability of the correlation index was evaluated by the Student's t-test. Quadratic error was $m_{\eta}=0.103$, with the reliability criterion $t_{p}=7.62$. Since the calculated values of $t_{p}$ are larger than the table values $t_{p}=3.55$ for $0.001 \%$ coverage, it can be considered that the calculated correlation index is quite reliable.

It is clear from Figure 4 that with increase in difference of values of the maximum entropy of adjacent areas, the accident rate decreases, but only to a certain limit. This is due to the fact that the accident rate is defined in the areas where the driver is in adaptation state and the road environment is considered comfortable. The subsequent increase in the entropy divergence in adjacent sections (Figure 4) leads to an increase in the relative accident rate on the road.

\subsection{Safety assessment of the motion conditions by maximum entropy}

Using values of the accident rate (represented by certain intervals) and the corresponding safety assessment of the section, established by the normative document [24], taking into account all the accidents (with victims and material losses), on the basis of dependence (Figure 4), estimation of change in the maximum entropy of the driver's perception field in adjacent sections of roads is proposed. The assessment of the sections' safety is given in Table 2.

Analysis of the output data of Table 1 and developed estimation of indicators of consistency of traffic conditions on adjacent sections (Table 2) shows that out of 45 kilometers 10 sections are safe, which is $22.2 \%$ of the total number of considered sections, 9 sections (20\%) belong to the unsafe, dangerous - 11 (24.4\%) and very dangerous 15 (33.4\%).

Assessment of the traffic conditions by the maximum entropy of the perception field allows to characterize the consistency of adjacent sections of roads based on indicators that guarantee the safe working conditions for the driver. Conditions on adjacent sections of roads are considered aligned if the maximum entropy values vary from $46 \%$ to $84 \%$, which when moving to the next section creates safe or low-risk driving modes. Adjacent sections, where the maximum entropy value changes by less than $46 \%$, are considered as consistent, as well, if they contain the number of road objects that are optimal for the driver to perceive. If the value of the maximum entropy is more than $84 \%$, the movement is considered dangerous or very dangerous, which indicates the inconsistency of the traffic conditions in the sections.

At the same time, results of the study are valid for drivers who have undergone measurements (26 people), an increase in the number of drivers with different psychological types $[6,8]$ can refine the results obtained and take into account their peculiarities when assessing the safety of adjacent road sections. The study used passenger cars for research purposes. Under these conditions, the factors characterizing «vehicles» and «drivers» in the " driver - vehicle - road environment» system remained unchanged or less changed. At the same time, additional experiments on trucks, buses, special vehicles will expand the data obtained and adjust the results of the study. In general, these refinements do not affect use of the developed method and evaluation of the road characteristics and will further diversify the road infrastructure for different users.

The obtained modal evaluation of the characteristics of traffic conditions allows to conclude on the safety of passage of adjacent sections. From a practical point of view, the characteristics presented make it possible to determine road safety during their design and operation.

\section{Conclusions}

The paper proposes a method for improving the traffic safety on adjacent sections of roads, which takes into account the human factor when assessing the environment. 
The maximum entropy of the field of perception is chosen as a criterion of the complex information influence of the road environment on the driver. The dependence of the aaccident rate on the maximum entropy of the driver's perception field is established. It is proved that the maximum entropy of the driver's perception field is an indicator of the of traffic conditions' safety on adjacent sections of roads.

The coordination scheme of adjacent sections of roads on the information links of the driver's interaction with the road environment is presented. For the first time, an estimate relate traffic conditions on adjacent sections of suburban roads by the maximum entropy of the driver's perception field was obtained. It is established that the conditions of motion in adjacent sections are considered consistent if the maximum entropy values differ by no more than $84 \%$. The practical value of the obtained modal assessment of the traffic conditions is that it allows to conclude that the passage of adjacent sections of roads is safe during their design and operation. In the case of discrepancy with the characteristics proposed in the work, in practice, the design of the road environment should be changed or its reconstruction made by reducing or increasing the number of elements on the road, combining them, reinstalling them and the like.

Results presented in thise paper can be used in the field of traffic organization and safety, namely in design of the road infrastructure, taking into account the human factor with which the driver perceives the environment (external environment).

\section{References}

[1] SCHLOSSER T., SCHLOSSER P. Traffic engineering analysis in the preparation and reconstruction of urban roads. Slovak Journal of Civil Engineering [online]. 2018, 26(2), p. 35-39. ISSN 1210-3896. Available from: https://doi.org/10.2478/sjce-2018-0012

[2] ZHU, Z-D., LU, Y-CH, FU, CH., XU, T. Research on the safety audit methods for two-lane highway based on HRV. Mathematical Problems in Engineering [online]. 2014, 308028, p. 1-6. ISSN 1024-123X., eISSN 1563-5147. Available from: http://dx.doi.org/10.1155/2014/308028

[3] MULLER-SCHNEIDERS, S. Vision-based detection of road users and infrastructure elements for automated driving. In: 20th International Conference on Research and Education in Mechatronics REM 2019 : proceedings [online]. 2019. ISBN 978-3-030-22063-1. Available from: https://doi.org/10.1109 / REM.2019.8744089

[4] BOROUJERDIAN, A. M., SEYEDABRISHAMI, E., AKBARPOUR, H. Analysis of geometric design impacts on vehicle operating speed on two-lane rural roads. Procedia Engineering [online]. 2016, 161, p. 1144-1151. ISSN 0000-2009. Available from: https://doi.org/10.1016/j.proeng.2016.08.529

[5] KAPSKI, D., KASYANIK, V., LOBASHOV, O., VOLYNETS, A., KAPTSEVICH, O., GALKIN, A. Estimating the Parameters of traffic flows on the basis of processing of localization data on the movement of vehicles. Communications - Scientific letters of the University of Zilina [online]. 2019, 21(2), p. 89-99. ISSN 1335-4205, eISSN 2585-7878. Available from: http://komunikacie.uniza.sk/index.php/communications/article/view/1474

[6] GAVRILOV, E. V., SARKISYAN, M. V. Psychological adjustment speeds / Psihologicheskoe regulirovanie skorostej dvizheniya (in Ukrainian). Vestnik HNADU. 2002, 17, p. 96-100. ISSN 2219-5548, eISSN 2521-1773.

[7] SINGH, G., SACHDEVA, S.N., PAL, M. M5 model tree based predictive modeling of road accidents on non-urban sections of highways in India. Accident Analysis and Prevention [online]. 2016, 96, p. 108-117. ISSN 0001-4575. Available from: https://doi.org/10.1016/j.aap.2016.08.004

[8] WANG, J.-Q., WU, J., LI, Y. Concept, principle and modeling of driving risk field based on driver-vehicle-road interaction. China Journal of Highway and Transport [online]. 2016. 29(1), p. 105-114. ISSN 1001-7372. Available from: https://doi.org/1001-7372(2016) 01-0105-10

[9] XIAN-QIANG, R., \& JIAN-YI, L. Factors contributing to freeway crashes and collisions: some measures and findings along TDM implementation. Communications-Scientific letters of the University of Zilina. 2010, 12(3), p. 75-79. ISSN 1335-4205, eISSN 2585-7878. Available from: http://communications.uniza.sk/index.php/communications/article/ view/935

[10] PRASOlENKO, O., BURKO, D., TOLMACHOV, I., GYULYEV, N., GALKIN, A., LOBASHOV, O. Creating safer routing for urban freight transportation. Transportation research procedia [online]. 2019, 39, p. 417-427. Available from: https://doi.org/10.1016/j.trpro.2019.06.044

[11] BABKOV, V. F. Ways to ensure road safety on the roads / Puti obespecheniya bezopasnosti dorozhnogo dvizheniya na dorogah (in Russian). In: Road design in difficult conditions / Proektirovanie avtomobilnyh dorog $v$ slozhnyh usloviyah: sb. nauch. trudov. Moskva: MADI, 1988, p. 4-16.

[12] SHEPElEV, V., ALFEROVA, I., SHUBEnKOVA, K. A method to calculate the change interval duration to ensure pedestrian safety. Transportation Research Procedia [online]. 2018. 36, p. 707-711. ISSN 2352-1465. Available from: https://doi.org/10.1016/j.trpro.2018.12.102 
[13] SEPPELT, B., TRENT, V. Potential solutions to human factors challenges in road vehicle automation. In: Road Vehicle Automation 3. Lecture Notes in Mobility [online]. MEYER, G., BEIKER, S. (eds.). Springer, Cham, 2016. ISBN 978-3-31-940502-5, eISBN 978-3-31-940503-2, p. 131-148. Available from: https://doi.org/10.1007/978-3-319-40503-2_11

[14] KULBASHNAYA, N. I. LINNIK, I. E. Application of information characteristics in models of driver's perception of road conditions. Eastern-European Journal of Enterprise Technologies [online]. 2015, 3(75), p. 27-32. ISSN 1729-3774, eISSN 1729-4061. Available from: http://dx.doi.org/10.15587/1729-4061.2015.42480

[15] COVER, T. M., THOMAS, J. A. Elements of information theory. 2. ed. Hoboken, New Jersey: John Wiley \& Sons, 2012. ISBN-13 978-0-471-24195-9.

[16] WANG, J., MAO, Y., L. JING, X. ZHANG, WANG W-X. Predictability of road traffic and congestion in urban areas. Plos One [online]. 2015, 10(4). ISSN 1932-6203. Available from: http://dx.doi.org/10.6084/m9.figshare.1294744

[17] SONG, C., QU, Z., BLUMM, N., BARABASI, A. L. Limits of predictability in human mobility. Science [online]. 2010, 327(5968), p. 1018-1021. ISSN 0036-8075, eISSN 1095-9203). Available from: https://doi.org/10.1126/science.1177170

[18] GALKIN, A., DAVIDICH, N., MELENCHUK, T., KUSH, Y., DAVIDICH, Y., LOBASHOV, O. Modelling truck's transportation speed on the route considering driver's state. Transportation research procedia [online]. 2018, 30, 207-215. Available from: https://doi.org/10.1016/j.trpro.2018.09.023

[19] GAVRILOV, E. V., GALKINA, N. G. Harmonization of external environment parameters on adjacent sections of the road (in Ukrainian). Avtomobillni Dorogi i Dorozhni Budivnictvo: Nauk.-Tekhn. Zb. 1989, 44, p. 100-104.

[20] KULBASHNAYA, N. I. Coordination of adjacent sections of roads / Soglasovanie smezhnyh uchastkov dorog. (in Ukrainian) Kommunalnoe Hozyajstvo Gorodov: Nauch.-Tekhn. Sb. 2007, 76, p. 324-328. ISSN 0869-1231.

[21] ORNATSKIJ, N. P. Features of the visual perception of road architecture by car drivers / Osobennosti zritelnogo vospriyatiya dorozhnoj arhitektury voditelyami avtomobilej (in Russian) Dorozhnye Usloviya $i$ Bezopasnost Dvizheniya: Sb. Nauch. Trudov. 1975, 52, p. 128-138.

[22] GAVRILOV, E. V., GRIDCHIN, A. M., RYAPUHIN, V. N. Systems engineering of roads / Sistemnoe proektirovanie avtomobilnyh dorog (in Russian). Belgorod: Izdatelstvo ASV, 1998.

[23] KLINKOVSHTEJN, G. I., AFANASEV, M. B. Traffic management / Organizaciya dorozhnogo dvizheniya: ucheb. dlya vuzov (in Russian). Moscow: Transport, 2001. ISBN 5-277-02240-6.

[24] SOU 45.2-00018112-007: 2008. Road safety. Public highways. The order of determining the areas and places of concentration of traffic accidents on public roads (Standard Organizations of Ukraine) / Bezpeka dorozhnogo ruhu. Avtomobilni dorogi zagalnogo koristuvannya. Poryadok viznachennya dilyanok i misc koncentracii dorozhno -transportnih prigod na dorogah zagalnogo koristuvannya. Standart organizacij Ukraini (in Ukrainian). Kiev: Ukravtodor, 2008. 